\title{
PADRE HENRIQUE VAZ: UM MESTRE INCOMPARÁVEL
}

\author{
Discurso pronunciado na solenidade de entrega \\ do título de Professor Emérito da Universidade Federal de \\ Minas Gerais ao Prof. Dr. Pe. Henrique Cláudio de Lima Vaz
}

Carlos Roberto Drawin*

Exmo. Prof. Francisco César de Sá Barreto, Magnífico Reitor da Universidade Federal de Minas Gerais, Exma. Profa, Vera Alice Cardoso Silva, DD. Diretora da Faculdade de Filosofia e Ciências Humanas, Exma. Profa. Telma de Souza Birchal, DD. Chefe do Departamento de Filosofia, Membros da Egrégia Congregação, Autoridades Civis e Eclesiásticas presentes, Senhora e Senhores, Caro Prof. Henrique Cláudio de Lima Vaz

Saudar, o meu querido mestre, na justa homenagem que lhe prestam a Universidade Federal de Minas Gerais e sua Faculdade de Filosofia e Ciência Humanas foi a tarefa, ao mesmo tempo, grata e árdua, a que fui incumbido pela generosidade dos meus colegas do Departamento de Filosofia. Grata, porque não me foi imposta como obrigação a ser cumprida na ritualística de uma cerimônia acadêmica, mas que nasce "pectore ab imo", do fundo do coração, daquele âmago, onde o reconhecimento da inteligência vai transfundir-se na carne do afeto. Árdua, porque todos aqueles que o conhecem, o sabem avesso aos encômios e exaltações e proverbialmente apegado ao que já foi descrito anteriormente, em outras homenagens, como "contenção jesuítica" e "discrição mineira". Porém, se a admiração e o louvor não podem ser

* Professor do Departamento de Filosofia/UFMG 
contidos é porque também sabemos que a magnanimidade do homenageado excede à sua modéstia. Pois, como nos ensina Aristóteles em sua "Ética a Nicômaco", distante do vaidoso, que arroga qualidades que não possui, o homem magnânimo não se desmerece do convívio com a grandeza, aceitando-a como uma espécie de "coroa das virtudes". O homem magnânimo, e só pode sê-lo quem possuir um caráter bom e nobre, sabe que a grandeza não pode ser encontrada quando a buscamos mas, como um esplendor da bondade, também não pode e nem deve ser evitada, por isso, recebe-a com moderado prazer.

Assim, justificado na ética aristotélica, que o homenageado tanto se empenhou em nos ensinar, posso contornar a objeção de seu constrangimento e prosseguir nessa "Laudatio Cordialis" retomando aquele mesmo espírito da "Laudatio Finalis" proferida pelo Pe. Fernado Bastos de Ávila, no encerramento da comemoração de seu septuagésimo aniversário. Naquela ocasião, o Pe. Ávila, com intimidade fraterna e evocando a oração de Santo Inácio, decifrou para nós o que seria o segredo da vida do Pe. Vaz: o autêntico - e desde então incessante - discernimento do Espírito a que se entregou o jovem mineiro quando, no final dos anos trinta, ingressou na Companhia de Jesus. Hoje, com respeito filial, permito-me retomar, passados mais dez anos, aquela oração do Pe. Ávila, ao mesmo tempo reza e discurso, que nos mostrou, de modo simples e sereno, a fonte cristã, límpida e inexaurível, de onde brotava esta vida vivida com extraordinária fecundidade. É imprescindível dize-lo, ainda que consciente de que esta é uma casa de ciência, ciosa de seu caráter laico e secular, pouco afeita a efusões piedosas. Mas, se é pelos frutos que as árvores são conhecidas, seria insensato, no momento em que louvamos os frutos desconhecer a árvore que os produziu. A árvore e suas raízes. Quais seriam, podemos nos perguntar, as raízes do Pe. Vaz?

A resposta, a tal indagação, deve ser a mais singela possível. Diria, inspirando-me livremente na "Fenomenologia" hegeliana, que o seu ponto de partida foi uma espécie de "certeza sensível", foi a imediatidade de um chão, onde ele pôde dar os primeiros e firmes passos de um itinerário que não cessou de se desdobrar e enriquecer. Chão ouro-pretano onde, ali no início do Bairro das Cabeças, perto da ponte do Rosário, ele teve a ventura de nascer, no aconchego de uma família que ainda trazia o que havia de melhor na antiga mineiridade: a fé sólida, a honradez, a moderação e o humanismo, cultivado tanto por seu pai, Teodoro, professor catedrático de Mineralogia na Escola de Minas, quanto por seu avô materno, Cláudio, pertencente àquela estirpe, já quase extinta, de médicos eruditos, a incutir no neto a disciplina da gramática latina.

Ao dedicar o segundo volume de seus "Escritos" à sua caríssima Ouro 
Preto, o Pe. Henrique Vaz dizia estar devolvendo à sua terra o produto amadurecido da semente que, em tempos idos, ali mesmo havia germinado. Mas não foi esta, a família e a cidade, a sua única pátria, a que seria para sempre resguardada, a resplandecer na memória. Em seu tocante depoimento autobiográfico, são revividos, com emoção, aqueles "anos friburguenses... os melhores, os sempre lembrados... a ilha silenciosa para onde navega o nosso coração, nas horas de tranqüila saudade, para levar a coroa sempre verde de uma recordação que não morre”. (Cf.: Meu Depoimento. In: Stanislaus Ladusans. Rumos da Filosofia Atual no Brasil: Em Auto-Retratos. São Paulo , Loyola, 1976)

A beleza poética desta evocação não traz somente o anelo da primeira juventude, mas revela a força plasmadora daqueles anos de austera formação intelectual no antigo escolasticado dos jesuítas em Friburgo, a permanência daqueles dias silenciosos e calmos, tão longe do horror de um mundo que estava sendo devastado pela guerra, e onde apenas se ouvia o ruído seco das páginas que eram passadas nas longas tardes de estudo. Foi esse o alimento - o da grande tradição clássica e medieval — que pôde robustecer aquela jovem inteligência, brilhante e inquieta, em que já despontavam, com inequívoco fulgor, as promessas de suas futuras realizações. Pôde robustecê-la mas, de modo algum, saciá-la. Ao embarcar para a Europa, com Fernando Ávila e João Bosco Burnier, para continuar a sua formação, o tímido estudante já deixava os primeiros traços de uma lenda. Alguns de seus colegas confidenciavam que ele não interrompia a concentração e a leitura sequer durante o café da manhã. Imagem que, mesmo inverídica, projetava as muitas esperanças que nele, então, se depositavam e, dentre elas, a de que seria o herdeiro espiritual do grande Leonel Franca.

Ainda que o nosso homenageado não goste dessas estórias, desautorizando-as energicamente, elas estão aí, incorporadas à lenda e, quanto a isso, ele nada pode fazer. Portanto, acrescento, "cum grano salis", para não aborrecê-lo em demasia, uma estorinha que eu mesmo ouvi e de pessoa tão próxima que eu seria capaz de apostar em sua veracidade. Durante um almoço na "çuria provincial" dos jesuítas, casa onde ele morava naquela época, um de seus colegas perguntou o significado da expressão "Aloha", conhecida saudação polinésia e nome de um bar das proximidades. O Pe. Vaz, impassível e jocoso, respondeu que aquele seria o grito de uma tribo guerreira. Informação que o seu colega avidamente registrou e logo utilizou, pouco tempo depois, numa conversa social, tendo sido imediatamente desmentido, para seu vexame, por um de seus ouvintes. As más línguas comentam que foi por esse motivo que o colega jesuíta do Pe, Vaz resolveu dedicar-se tardiamente à antropologia. 
Esse episódio anedótico, no qual transparece a jovialidade que se esconde sob a aparente sisudez de nosso filósofo, também testemunha a sua enorme autoridade intelectual, a que havia começado a nascer, quando ainda estudante, antes mesmo que ele iniciasse a sua douta produção filosófica.

Em Roma, em meio às muitas ruínas do imediato pós-guerra, a sua inteligência, insaciada e insaciável, iria lançar-se à assimilação das inquietações de um conturbado mundo moderno, e respirar os novos ares da renovação católica: os da "nouvelle théologie", dos escritos de De Lubac, Blondel, Teilhard de Chardin, e do personalismo de Mounier. Mas também surpreenderse com Sartre, no zênite de sua fama, e fazer os primeiros contatos com o Marxismo. Toda uma efervescente literatura que, não obstante, acabou abrigando-se sob a imponente abóbada do pensamento platônico, a assinalar a jamais desmentida primazia da ontologia clássica.

Se eu menciono tudo isso, a lenta e sutil urdidura de leituras e influências, não é - Deus nos livre! - com o intuito insensato e arrogante de iniciar a reconstituição de um percurso filosófico singular e já sedimentado numa obra riquíssima e multifacetada. Obra construída num labor silencioso e humilde, mas cuja originalidade e rigor, sem nenhuma concessão aos modismos, começa a alcançar crescente ressonância, tornando-se objeto de numerosos estudos. As minhas rápidas alusões não têm outro propósito, senão esboçar os contornos do que seria quase um enigma: como fios aparentemente tão dispersos puderam tecer tão magnífica tapeçaria? Como uma erudição tão vasta deixou-se plasmar numa síntese tão poderosa, em sua paradoxal interpenetração de coerência lógica e abertura sistemática?

Para os que não o leram e para que não pensem que essas interrogações destinam-se ao elogio fácil e esgotam-se na retórica de uma solenidade, gostaria de indicar apenas um dado, meramente quantitativo, mas que não deixa de ser, em si mesmo, eloqüente. Deixando de lado centenas de editoriais, resenhas e artigos publicados, e que não foram por mim compulsados, eu aferi aproximadamente 5.600 notas bibliográficas, nos seis volumes dos " $E s$ critos de Filosofia" e nos dois volumes da "Antropologia Filosófica". Não se trata de mera bibliografia, mas notas contendo freqüentemente mais de uma referência bibliográfica, acompanhada de precisos e preciosos comentários.

Mas esse é um dado menor e, por isso, eu retorno com outra interrogação ao enigma dessa filosofia: como ela pôde ser tão bem sucedida em sua complexa unidade e em sua consistência interna, sem que jamais o seu autor cedesse à desrazão e nem se concedesse à descrença?

Eu não saberia responder. Só uma leitura paciente e meditada dos textos poderia nos ajudar, sem leviandade, a aclarar o problema. Porém, nesse mo- 
mento, não é o problema que me instiga, mas é o mistério que me comove. E, embora sabendo da autonomia hermenêutica da obra em relação ao seu autor, é do elevado cimo de sua consecução que creio poder discernir melhor o homem que a construiu. Aquele que, nem bem chegado "al mezzo del cammin", ainda no vigor de sua juventude, ao reconstituir o seu itinerário metafísico, podia perguntar com invejável liberdade: "quod mentis sectabor iter?" Que caminho de pensamento seguir? Com invejável liberdade, porque já havia respondido à uma questão mais fundamental, aquela, tomada de um verso de Ausônio e celebrizada no sonho cartesiano, "quod vitae sectabor iter?" Que caminho de vida seguir?

Sabemos qual foi, na sua retidão exemplar: os quase cinqüenta anos de magistério ininterrupto, a investigação incansável, a permanente disponibilidade em ouvir e orientar, a paciência do pensamento, a firmeza da crítica no acolhimento do outro, mesmo nos tempos mais adversos. Tudo isso - como tantos poderiam testemunhar bem melhor do que eu - foi assumido com perfeita espontaneidade, sem a menor sombra de enfatuação, sem jamais esmorecer na fidelidade à verdade. "Quod vitae sectabor iter?" Que caminho de vida seguir? Certamente aquele que em sua "Laudatio Finalis" o Pe. Fernando Bastos Ávila nos revelou. Aquele que o jovem Henrique Vaz, no solitário discernimento do Espírito, soube transformar numa opção irreversível de abertura para o mundo, mas sem se deixar seduzir por seus muitos descaminhos, porque possuído pela nostalgia ontológica da verdadeira pátria. Todas as outras, embora inesquecíveis, não foram mais do que estações nesse caminhar: a insubstituível Ouro-Preto, o acalanto da família, a descoberta da filosofia nos anos friburguenses, o entusiasmo dos passeios romanos, os compromissos da maturidade política, o quotidiano escrupuloso da docência, o recôndito da experiência religiosa.

O que vale, portanto, este título de "Professor Emérito" para uma pessoa que fulgura em sua simplicidade? Não sei, mas creio que ele o aceita como homem magnânimo. A ética aristotélica, porém, é insuficiente para compreender o mistério de uma existência que acolhe o verdadeiro Mistério na aguda consciência do horizonte intranscendível da finitude. Consciência dramática, não trágica, porque possuída pela esperança indelével, cantada nos versos que o Pe. Henrique Vaz colocou na conclusão de sua "Antropologia Filosófica". Os da bela seqüência da liturgia Pascal:

"Mors et Víta duello conflixere mirando:

dux vítae mortuus, regnat vívus"

"Morte e vida travaram admirável combate;

O Senhor da vida, tendo morrido, agora reina vivo" 
Este, porém, é um limiar que a filosofia não atravessa. Mas não nos reunimos aqui para discutir a obra, mas sim para louvar o homem. E não podemos faze-lo calando a sua verdade. Esta é uma noite de festa, de congraçamento e de alegria. Termino, pois, esta minha "Laudatio ex corde" com uma citação que visa aplacar os que, porventura, ficaram sobressaltados com os versos da liturgia cristã. Trata-se do fragmento de um pequeno poema de Nietzsche, de sua "Canção da Embriaguez":

"Weh spricht: Vergeh!

Doch alle Lust will Ewigkeit -

— will tiefe, tiefe Ewigkeit!"

"A dor diz: passa, morre!

Toda alegria porém, quer eternidade -

— quer profunda, profunda eternidade!" 